\title{
MECANISMOS ENUNCIATIVOS NA PRODUÇÃO TEXTUAL: REFLEXÕES SOBRE A NOÇÃO ONDE
}

\section{ENUNCIATIVE MECHANISMS IN TEXTUAL PRODUCTION: REFLECTIONS ON THE NOTION "WHERE"}

\author{
Cássia Regina Coutinho SOSSOLOTE ${ }^{1}$ \\ Marília Blundi ONOFRE²
}

\begin{abstract}
Resumo: $O$ presente artigo tem como objetivo analisar ocorrências com a noção linguística onde presentes em textos produzidos por alunos de graduação de instituição de ensino superior que apresentam valores não validados pelas gramáticas de Língua Portuguesa. Para a análise de algumas ocorrências com onde, tomamos como referência a Teoria das Operações Predicativas e Enunciativas tal como foi proposta por Antoine Culioli a fim de demonstrarmos como ela contribui para ampliar a compreensão dos usos dessa marca em contextos/cotextos não previstos pelas gramáticas, que descrevem a língua a partir das categorias herdadas da tradição greco-latina com implicações significativas para a descrição gramatical. Os enunciados analisados compõem textos de alunos que se encontravam em processo de apropriação, de aquisição da língua escrita.
\end{abstract}

Palavras-chave: Marcas Linguísticas. Operações de Linguagem. Noção. Operação de Localização. Invariância.

\begin{abstract}
This article aims to analyze occurrences with the linguistic notion "where" present in texts produced by undergraduate students of a higher education institution that shows values not validated by the grammars of Portuguese language. For the analysis of some occurrences with onde [where], we will take as reference the Theory of Predictive and Enunciative Operations as proposed by Antoine Culioli in order to demonstrate how it contributes to broadening the understanding of the uses of this mark in contexts/cotexts not previewed by grammars, which describethelanguagefrom the categories inherited from the GrecoLatin tradition with significant implications for grammatical description. This is based on data which are representative of text clippings from students who were in the process of appropriation, the acquisition of the written language.
\end{abstract}

Keywords: Linguistic Marks. Language Operations. Notion. LocationOperation. Invariance.

\footnotetext{
1 Universidade Estadual Paulista "Júlio de Mesquita Filho" (UNESP), Araraquara, São Paulo, Brasil; cassia. sossolote@unesp.br; https://orcid.org/0000-0001-6264-3499
}

2 Universidade Federal de São Carlos (UFSCar), São Carlos, São Paulo, Brasil; blundi@uol.com.br; https://orcid.org/0000-0002-7075-310X 
- Mecanismos enunciativos na produção textual: reflexões sobre a noção onde

\section{Introdução}

O presente artigo tem como objetivo apresentar e discutir o uso da noção onde em contextos/cotextos não previstos pelas gramáticas de Língua Portuguesa. Para atingir tal objetivo, o artigo contará com cinco seções. Na primeira, apresentaremos a estrutura do presente texto. Na segunda, algumas ocorrências de onde bem como as hipóteses que formulamos, inicialmente, sobre o seu uso por alunos que estavam no início de uma graduação. Na terceira seção, recuperaremos a descrição sobre o modo como as gramáticas de Língua Portuguesa prescrevem o valor desse advérbio relativo. Na quarta, será problematizada a descrição que se encontra nas gramáticas tradicionais com base na Teoria das Operações Predicativas e Enunciativas, doravante TOPE, a fim de validar as ocorrências dessa marca em textos produzidos por alunos de uma IES. Na última seção, apresentada a título de conclusão, teremos elementos para demonstrar que existe uma relação de imbricação entre teoria e descrição gramatical. Reafirmaremos a tese do linguista genebrino Ferdinand de Saussure a respeito do fato de que "o ponto de vista cria o objeto".

\section{O uso de onde em contextos não validados pelas gramáticas pedagógicas}

Todo o leitor com formação no campo de conhecimento das Letras seria capaz de identificar, ainda que em linhas bastante gerais, o movimento que surgiu nas décadas de 80 e 90, que culminou com a crítica tanto à prescrição gramatical quanto ao ensino da Língua Portuguesa, uma vez que os professores considera(va)m o domínio da nomenclatura e das definições gramaticais das quais os gramáticos partem para analisar um conjunto de fatos ou fenômenos da Língua Portuguesa, a saber, ocorrências de textos literários como se fossem propedêuticos ao uso do bom Português pelos alunos a quem ela deveria ser ensinada desde os anos iniciais.

Imprecisões conceituais foram demasiadamente apontadas assim como foi criticado o ensino da metalinguagem oriunda das gramáticas de Língua Portuguesa de natureza prescritiva, já que se considerou que os alunos não se tornariam mais proficientes em sua língua materna se se tornassem capazes de realizar análises linguísticas como se fossem linguistas em iniciação.

Vale destacar que a Sociolinguística, entre as linhas teóricas que mais influenciaram as críticas às representações dos professores sobre "a" Língua Portuguesa, ocupou lugar privilegiado pelo fato de ela chamar a atenção para o fenômeno da variação. Se, por um lado, buscou-se demonstrar que a língua não é um fenômeno homogêneo, por outro, 
os variacionistas convidaram os professores a valorizarem o saber linguístico do aluno mesmo quando ele não coincidisse com o da variante culta.

Embora essa discussão circule entre pesquisadores pertencentes ao campo da Linguística há mais de três décadas, retomamos essas questões para afirmar que ela resolveu parcialmente os dilemas dos professores de Língua Portuguesa. Com o objetivo de demonstrar que havia uma outra metodologia para o ensino da língua materna que ofereceria ao aluno a possibilidade de realizar uma atividade de natureza reflexiva, baseada no uso $\leftrightarrow$ reflexão $\leftrightarrow$ uso, foi apresentada na Proposta Curricular de Língua Portuguesa $1^{\circ}$ grau em suas primeiras edições breves considerações sobre a atividade epilinguística, nova metodologia na qual o professor poderia se apoiar para conscientizar os alunos sobre usos, muitas vezes desviantes, apreendidos nos textos que produzem. É importante dizer que os documentos oficiais que incorporaram os discursos de pesquisadores em relação ao ensino da gramática não apresentaram referências sobre o autor que desenvolveu este conceito que, articulado a outros conceitos, permite que se discuta a relação língualinguagem (CULIOLI, 1990).

O professor de Língua Portuguesa, no entanto, continua a enfrentar situações conflituosas. A correção de texto constitui uma situação dilemática, por excelência, uma vez que aquele que corrige o texto pode não coincidir com aquele que se serve de metodologia que permitiria a reflexão sobre as ocorrências desviantes, ou não, utilizadas pelos alunos na atividade de produção de textos.

Foi justamente no processo de correção de textos produzidos por alunos para quem, geralmente, o curso de Pedagogia foi sua primeira graduação que o objetivo deste artigo foi ganhando contorno. Mesmo na condição de professores universitários, capazes de recuperar as críticas feitas ao ensino de Língua Portuguesa com foco nos limites da descrição gramatical, no processo de correção dos textos dos alunos, acabamos nos apoiando na prescrição que consta, como demonstraremos, não somente em gramáticas pedagógicas como em descrição de usos validados pela tradição gramatical, descritas, por sua vez, por pesquisadores de notório saber.

A seguir, apresentaremos uma amostra de enunciados extraídos de produções de texto de alunos com a ocorrência da marca onde, a que já nos referimos, que constituem para os seguidores das gramáticas tradicionais um desvio em relação à norma, validada para o uso da variante culta. Tais produções textuais escritas são relatos de estágio realizados por licenciandos do curso de Pedagogia na modalidade semi-presencial, cujos Orientadores de Disciplina eram docentes da UNESP. 
Enunciados:

(1) PROJETO "Musicalidade". Esse projeto contribuiu para que os alunos conhecessem um universo musical diferente do que estavam habituados, erudito, embora as músicas utilizadas fizessem parte do repertório infantil. As músicas foram usadas como apoio pedagógico nas atividades de alfabetização e como fechamento foi montado um coral infantil onde os participantes fizeram uma apresentação de Natal. (COMS) ${ }^{3}$

(2) Do $1^{\mathrm{o}}$ ao $5^{\mathrm{o}}$ ano, a prática pedagógica desenvolvida nesta unidade escolar está embasada nas apostilas NAME contratada pela Secretaria Municipal de Educação de Botucatu e, no caso de Ciências, no Projeto Ciência Para a Gente (CTC/Sangari). Adequações são feitas pelos professores, embasados nos PCN, do Ensino Fundamental I, e visam acompanhar as mudanças que ocorrem na sociedade, onde o professor é mediador da aprendizagem. (COMS).

(3) Observei uma aula de capoeira, onde o professor deixa os alunos à vontade, ensinando alguns a tocarem berimbau, outros fazem movimentos e outros ainda querem atenção, conversar, e ele abre esse espaço. (RAdeJFP).

(4) Texto da apostila do município (grupos alimentares). Após a leitura, onde cada aluno lia uma parte e o professor explicava, foi trabalhada a interpretação da leitura, utilizando exemplos e preenchendo as atividades também na apostila. (RAdeJFP).

(5) Criação e confecção de um jogo pedagógico, onde as crianças aprendem brincando a valorizar o meio ambiente, cuidar dele e regras de boa convivência com a natureza. (RAdeJFP).

Vale ressaltar que, no processo de correção dos textos dos alunos, ao observar o uso recorrente dessa marca, formulamos duas hipóteses que não se sustentaram. A primeira dizia respeito à imagem que os alunos fazem da escrita. Onde parecia estampar uma formalidade própria ao texto escrito. A segunda nos levou a sustentar a hipótese de que o emprego da marca onde constituía um desvio gramatical. Para nós, a leitura de textos acadêmicos faria com que eles substituíssem essa marca por outras. Essa hipótese, certamente, fez com que validássemos sem perceber as normas prescritas pela gramática, como já foi dito, como se a metalinguagem com a qual os gramáticos operam desse conta

3 As siglas que se encontram no final das ocorrências constituem uma estratégia para garantir o anonimato dos autores. 
de descrever senão todos os fenômenos linguísticos pelo menos grande parte deles.No entanto, fizemos a tempo uma mea culpa: se a marca onde é tão recorrente nos textos dos alunos, é preciso explicar o seu valor. Para os adeptos da TOPE, não bastaria avaliar negativamente os usos que os alunos fazem nos textos escritos que produzem, atribuindoos, no limite, à interferência da oralidade na escrita. O objetivo da TOPE é outro: quer-se compreender o sentido de onde em novos contextos/cotextos enunciativos.

\section{As gramáticas tradicionais, a categorização e definição do uso de onde}

Para tomarmos conhecimento a respeito do modo como as gramáticas classificam e definem o uso do advérbio onde, consultamos Bechara (s/d), Bechara (2009), Rocha Lima (1994) e Neves (2000).

Na sequência, passaremos a apresentar as definições que localizamos nas gramáticas. Bechara define onde como "advérbio relativo que, como os pronomes relativos, servem para ligar a oração a que pertencem com a outra oração" (BECHARA, s/d, p. 154). Diz Bechara: "Nas idéias de lugar empregamos onde em vez de em que, no qual (e flexões)" (ibid., p. 154). O exemplo que encontramos nessa gramática para ilustrar o uso de "onde" foi A casa onde mora é excelente, cuja forma pode se alterar se o verbo da oração na qual ele se encontra for transitivo indireto ou intransitivo como ocorre nas frases que seguem: (1) "O sítio aonde vais é pequeno.", (2) "É bom o colégio donde saímos." (ibid., p. 154). O autor mantém a mesma descrição em gramática publicada em 2009. Nessa gramática, restringe-se à especificação das partículas que não podem ser comutáveis com "onde" e a afirmação de que o seu uso é recorrente entre escritores brasileiros e escritores portugueses. A descrição, portanto, focaliza frases sem contexto que se orientam pela norma e não textos de sujeitos que se encontram em processo de aquisição da língua escrita que nos permitiria flagrar os mecanismos enunciativos que sustentam o uso desse advérbio relativo.

Em lugar de em que, de que, a que, nas referências a lugar, empregam-se, respectivamente, onde, donde, aonde (que funcionam como adjunto adverbial ou complemento relativo).

O colégio onde estudas é excelente.

A cidade donde vens tem fama de ter bom clima.

A praia aonde te diriges parece perigosa.

Modernamente, os gramáticos têm tentado evitar o uso indiscriminado de onde e aonde, reservando o primeiro para a idéia de repouso e o segundo para a de movimento: 
- Mecanismos enunciativos na produção textual: reflexões sobre a noção onde

O lugar onde estudas...

O lugar aonde vais...

Esta lição de gramática tende a ser cada vez mais respeitada na língua escrita contemporânea, embora não sejam poucos os exemplos em contrário, entre escritores brasileiros e portugueses4. (BECHARA, 2009, 487-488, grifo nosso).

Se compararmos as definições de Bechara (s/d, 2009) a de Lima (1994), verificaremos que a única diferença consiste na especificação da oração que onde encabeça, a saber, orações adjetivas, que para Bechara (2009) podem se tratar de orações adverbiais ou completivas nominais.

Advérbios relativos são os advérbios onde, quando, como, empregado "com antecedente", em orações adjetivas.

Exemplos:

Fica ali a encruzilhada/onde ergueram uma cruz de pedra.

Era no tempo/quando os bichos falavam...

Merece elogios o modo/como tratas os mais velhos. (LIMA, 1994, p. 176, grifo nosso).

Neves (2000), em diferentes pontos de seu texto, apresenta descrição de uso de onde, com foco nas situações em que seu uso é abonado ou não pela gramática tradicional.

onde $\rightarrow$ Ver aonde.

1. Onde refere-se a lugar e indica permanência. É *advérbio interrogativo ("em que lugar...?"), * ONDE éque ele está?(A).

* pronome relativo ("no qual (lugar)"). *O mau tempo obrigou o avião a descer na Itália, ONDE Felisbina se especializou em operetas. (ACT).

\footnotetext{
4 Há um paradoxo que não temos como resolver e que não está entre os objetivos deste artigo. Quando dissemos que as gramáticas pedagógicas prescrevem usos com base em frases oriundas de textos literários, não quisemos dizer que o texto literário é produzido com base na norma. Os processos criativos levam, em muitos contextos, a subverter a norma prescrita pelos gramáticos. Não nos esqueçamos de fato bastante repisado nos cursos de Letras, de que o escritor cujas obras são reconhecidas como tendo valor literário possui licença poética para utilizar recursos expressivos ou subverter as normas prescritas pelo cânone gramatical. Em relação aos objetivos pontuados neste texto, a descrição que será feita não tem como escopo a prescrição. Ao contrário, queremos demonstrar o acerto no uso de ocorrências que seriam consideradas desviantes sob outro ponto de vista.
} 
Entretanto, como pronome relativo, onde vem sendo usado sem referência a lugar, simplesmente equivalendo a em que, no qual, o que é condenado nas lições normativas. São contextos como este: *É importante destacar as atividades EM QUE a preocupação social, religiosa e cultural da Igreja Universal alcança grande relevância. (VEJ).

Exemplos desse uso condenado são estes:

* Nos casos ONDE ocorrem pressão de artesianismo no lençol freático ou fuga de água no furo deverão ser anotadas as profundidades das ocorrências e do tubo de revestimento. (PRP).

* A edição de 16 de abril traz um artigo sobre a lógica "fuzzy", teoria matemática ONDE elementos podem pertencer apenas parcialmente a conjuntos. (FSP).

2. A combinação da preposição a com o advérbio ou pronome relativo onde é aonde ("para onde", indicando direção).

O uso de onde por aonde é condenado nas lições tradicionais.

Entretanto, são ocorrentes construções como: * Genebra, a eqüidistante, é o pique ONDE ides sempre repousar do pega-pega da vida agitada. (AM)

(NEVES, 2003, p. 557-558)

aonde $\rightarrow$ Ver onde.

Aonde é a combinação de preposição a com o advérbio ou pronome relativo onde. Em princípio, corresponde, pois, a para onde, indicando direção. * "AONDE você quer chegar?", perguntou Isabella, vislumbrando segundas intenções. (ACM). * De outra vez eu me encontrava num cemitério andaluz-AONDE fora levar um amigo morto de beribéri. (AL).

Essa é a recomendação de uso, atualmente, para a língua culta, embora seja generalizado o uso de aonde por onde, e vice-versa, uso que, aliás, também se verificava em escritores clássicos. 1) $A$ senhora sabe AONDE eu posso encontrar esse pai-de-santo? (AGO) 2) Ali AONDE? (CD).

Onde é advérbio ou pronome relativo, indicando permanência.

(NEVES, 2003, p. 77) 
Das definições apresentadas, pode-se depreender que gramáticas produzidas em diferentes momentos e sob diferentes influências descrevem o uso de onde de forma equivalente, se se considerarem as classes e as funções atribuídas a essa marca ${ }^{5}$.

\section{As oposições entre a Teoria das Operações Predicativas e Enunciativas (TOPE) e as Gramáticas Tradicionais}

A TOPE, teoria de base operatória, contrapõe-se às gramáticas de Língua Portuguesa por princípio pelo próprio fato de seu objeto de pesquisa não ser o mesmo das gramáticas. O seu objeto, à diferença das gramáticas de Língua Portuguesa,não tem a língua como ponto de partida, particularmente as línguas ocidentais, cujo trabalho de descrição ocorre com base nas categorias oriundas da tradição greco-latina.

O seu objeto tem um alcance maior cuja realização depende de um projeto no qual precisariam estar envolvidos pesquisadores que realizassem seus trabalhos de pesquisa a respeito de línguas pouco conhecidas cujas categorias não são correlatas a de vernáculos que têm maior circulação no mundo contemporâneo.

O objeto de pesquisa da TOPE e, portanto, dos pesquisadores que a tomam como referência, consiste em apreender a atividade de linguagem por meio da diversidade das línguas naturais que nem sempre estabelecem entre si relações de equivalência e de correspondência.

E qual é a diferença entre a TOPE e as gramáticas de Língua Portuguesa em relação ao emprego da marca onde?

A TOPE, apesar de não contestar as categorias linguísticas que têm uma materialidade inegável, não parte delas para apreender a atividade de linguagem, de natureza sociocognitiva. É justamente porque os sistemas linguísticos não são intercambiáveis que as regularidades não podem ser compreendidas, cotejando-se línguas cujas categorias nem sempre coincidem entre si. Para compreender processos invariantes entre línguas que apresentam diferenças categoriais, Antoine Culioli (1990), na análise dos enunciados produzidos por enunciadores, preocupa-se em identificar operações de linguagem responsáveis pela produção das formas linguísticas em diferentes línguas. Como da perspectiva da TOPE, línguas naturais e linguagem não se confundem, o autor define a atividade de linguagem com base nas operações de representação, de

5 Não nos passa despercebido o fato de que Neves (2000), na atividade que realiza, parte sempre de excertos que compõem textos atuais e autênticos. 
referenciação e de regulação. Começa aqui a se delinear de forma mais precisa a diferença entre a TOPE e as gramáticas.

Reconhece-se na TOPE que a língua só pode constituir um ponto de partida se, por meio da metalinguagem formulada por Antoine Culioli, conseguirmos apreender vestígios da atividade de linguagem, atividade inata que torna possível a operação de referenciação, por exemplo. Referenciar, da perspectiva da TOPE, implica tanto a capacidade de os indivíduos construírem sistemas simbólicos como a de construírem valores referenciais na instância da língua por meio de textos orais e de textos escritos. É por meio da atividade de referenciação tal como se materializa na instância da língua que podemos ter acesso à atividade de representação, de construção de representações mentais.

Culioli distingue os signos, que são da ordem da língua, das noções, que são da ordem da linguagem, a que não temos acesso, ou melhor, a que temos acesso somente por meio de operações que estão na base da constituição de enunciados.

Ainda que a linguagem seja invisível, Culioli não foi ingênuo. A metalinguagem que formulou com rigor coloca em cena a atividade de representação, de representações mentais, que dão contorno à noção. A este propósito diz Culioli (1990, p. 69, tradução nossa $\left.{ }^{6}\right)$,

Uma noção pode ser definida como um conjunto complexo de propriedades físico-culturais estruturadas e não deve ser igualada a rótulos lexicais ou itens reais. As noções são representações e devem ser tratadas como tal: elas simbolizam propriedades (o termo é usado aqui de uma forma muito extensa e solta) derivadas da interação entre pessoas e pessoas, pessoas e objetos, restrições biológicas, atividade técnica etc.

É possível deduzir, com base nessa citação, que as noções são particulares e individuais e não podem prescindir dos universos extralinguísticos (empíricos) e linguísticos.

6 No original: "A notion can be defined as a complex bundle of structured physico-cultural properties and should not be equated with lexical labels or actual items. Notions are representations and should be treated as such: they epitomize properties (the term is used here in a very extensive and loose way) derived from interaction between persons and persons, persons and objects, biological constraints, technical activity, etc.". 
- Mecanismos enunciativos na produção textual: reflexões sobre a noção onde

Para apreender a operação de representação mental, possível graças à atividade de linguagem, Culioli (1990, p. 180, tradução nossa) definirá as operações de linguagem como

Uma relação tríplice entre representação mental, processos referenciais e regulação é um pré-requisito para qualquer atividade conceitual simbólica mediada por sequências de texto (e/ou gestos) que os sujeitos produzem e reconhecem como formas significantes interpretáveis. Representação é um complexo de muitos níveis de operações de ordem n. A representação é um complexo de operações de ordem enésima, de muitos níveis, baseado em uma operação primitiva chamada operação de localização (Francês, operação de repérage).

Apesar de as noções constituírem um bloco indivisível, fragmentada em eventos enunciativos cujos enunciados resultam de operações que são da ordem da linguagem, a operação de localização tal como foi formulada por Culioli constitui um caminho para a análise de ocorrências com a marca onde.

Vejamos o que diz o autor a respeito dessa operação de linguagem.

7 No original: "A threefold relationship between mental representation, referencial processes and regulation, is a prerequisite to any symbolic conceptual activity mediated by text (and/or gesture) sequences that subjects produze and recognize as interpetable meaningul shapes. Representation is a many-levelled complex of $n$-th order operations. Representation is a many-levelled complex of $n$-th order operations, based on a primitive elementary operation called an operation of location (French, opération de repérage).". 
Representação é um complexo de operações de ordem enésima de muitos níveis, baseada em uma operação elementar primitiva chamada operação de localização (French, opération de repérage). O conceito de localização está ligado à ideia de localizar um termo em relação a outro. Dizer que x está localizado em relação a y significa que x está situado com referência a y, se o último, que é assim um localizador, está ele próprio localizado por outro local, ou se ele é uma origem. Não há nada que impeça que um termo seja localizado em relação a si mesmo, ou um termo que era o localizador em uma relação, a partir de então se tornar o locatum em uma relação recíproca de localização. A ideia básica é que um objeto só adquire uma forma e um valor por meio de um esquema dinâmico de localização. (CULIOLI, 1990, p. 180-181, tradução nossa ${ }^{8}$ ).

Qual é o alcance da TOPE para a análise dos enunciados citados produzidos por alunos no início de sua graduação?

Considerando a questão formulada acima, procuraremos respondê-la pela análise apresentada na seção seguinte.

\section{Análise das ocorrências segundo a Teoria das Operações Predicativas e Enunciativas}

Orientando-nos pelas considerações feitas por Culioli de que as representações são construídas com base em termos que localizam outros, poderíamos tentar identificar a natureza de cada um dos termos postos em relação pela marca onde, nos enunciados seguintes:

(1) As músicas foram usadas como apoio pedagógico nas atividades de alfabetização e como fechamento foi montado um coral infantil onde os participantes fizeram uma apresentação de Natal. (COMS).

(2) Adequações são feitas pelos professores, embasados nos PCN, do Ensino Fundamental I, e visa acompanhar as mudanças que ocorrem na sociedade, onde o professor é mediador da aprendizagem. (COMS).

\footnotetext{
8 No original: "Representation is a many-levelled complex of n-th order operations, based on a primitive elementary operation called an operation of location (French, opération de repérage). The concept of location is linked to the idea of locating one term relative to another. To say that $x$ is located relative to $y$ means that $x$ is situated with reference to $y$, whether the latter, which is thus a locator is itself located by another location, or whether it itself is an origin. There is nothing to prevent a term from being located relative to itself, or a term which was the locator in one relation-ship from then becoming the locatum in a reciprocal relationship of location. The basic idea is that an object only acquires a form and a value by means of a dynamic scheme of location".
} 
- Mecanismos enunciativos na produção textual: reflexões sobre a noção onde

(3) Observei uma aula de capoeira, onde o professor deixa os alunos à vontade, ensinando alguns a tocarem berimbau, outros fazem movimentos e outros ainda querem atenção, conversar, e ele abre esse espaço. (RAdeJFP).

(4) Texto da apostila do município (grupos alimentares). Após a leitura, onde cada aluno lia uma parte e o professor explicava, foi trabalhada a interpretação da leitura, utilizando exemplos e preenchendo as atividades também na apostila. (RAdeJFP).

(5) Criação e confecção de um jogo pedagógico, onde as crianças aprendem brincando a valorizar o meio ambiente, cuidar dele e regras de boa convivência com a natureza. (RAdeJFP).

Nos enunciados acima, os sintagmas nominais apresentam uma regularidade. Onde coloca em relação dois termos, quais sejam, um localizador e um localizado. Nesse sentido, no enunciado (1), <coral infantil $>$ é um localizador para <participante $\rangle$, da mesma forma que, em (2),<sociedade $>$ o é para $<$ professor $>$. Na terceira, quarta e quinta ocorrência, observamos a mesma relação: <aula de capoeira > é um localizador para <professor >; $<$ leitura $>$ para <cada aluno $>$ e <jogo pedagógico $>$ para $<$ crianças $>$.

Dada a extensão da noção de localizador do ponto de vista qualitativo instanciase entre localizador e localizado uma relação entre todo e parte. Embora o localizador não designe lugar, certamente eles apresentam propriedades espaço-temporais, fato que faz com que onde tenha, nesses contextos, seu valor locativo enunciado em virtude das unidades que são colocadas em relação.

Assim, podemos considerar que em (1) foi montado um coral infantil onde os participantes fizeram uma apresentação de Natal, de onde se instauram as relações $<$ coral infantil $>$ - <participantes> que podem estabelecer as seguintes relações:

1a) < Há um coral infantil < Há participantes que são participantes deste coral infantil $<$ Participantes do coral infantil $<$ Coral infantil cujos participantes.

1b) < Há um coral infantil < Há participantes que estão neste coral infantil $<$ Participantes no coral infantil < Coral infantil onde participantes.

Trabalhamos com o fato de que os alunos, diante dessas duas possibilidades de referenciar a relação <coral infantil $>-<$ participantes $>$, quais sejam, (i) <participar de algo $>$ $e$ (ii) < participar em algum lugar >, optaram por referenciá-la por meio da explicitação da marca de espacialidade presente em (ii), <participar <de algo $>$ em algum lugar $>$, o que justificaria o emprego de $\langle$ onde $\rangle$, que é rejeitado pela gramática normativa. Ao mesmo 
tempo, podemos considerar que esses dois caminhos apontados em (i) e (ii) partem de diferentes pré-construídos, uma vez que respondem, respectivamente, às perguntas: (i) Eles são participantes de quê? e (ii) Eles são participantes, onde? Tais perguntas implícitas, que estariam na organização da enunciação, gerariam valores distintos, indicando em (i) uma qualificação, tal como <participantes do coral>, e, em (ii), uma indicação espacial, tal como <participantes no coral>.

O que apresentamos aqui são reflexões acerca de uma ocorrência que tem se mostrado muito presente nos usos do Português. Reconhecemos, no entanto, que a análise deve ser ampliada à medida que nossas análises são preliminares, apesar de julgarmos que ela pode ser estendida a outras ocorrências de onde.

Concluiremos esta seção retomando a relação linguagem-línguas naturais. Quando as representações mentais se materializam na instância da língua por meio de textos orais e de textos escritos, as relações que os termos estabelecem entre si constituem uma relação predicativa cujos termos são ordenados e orientados, podendo estabelecer entre si uma relação entre todo e parte, quer o localizador designe acontecimentos, processos, etc.

\section{A título de conclusão}

Com base nas análises desenvolvidas, constatamos que as hipóteses formuladas, inicialmente, não se sustentam quando tomamos a TOPE como referência, dado que o emprego da marca onde não constitui um recurso formal e nem mesmo uma marca desviante. Foi possível observar que a marca onde veicula um valor ainda não reconhecido pelos estudos gramaticais. A análise proposta pela TOPE aponta para um lugar híbrido a ser validado pelo emprego dessa noção, uma vez que se reconhece uma confluência possível entre os valores de qualificação e de espacialidade.

Buscamos demonstrar, ainda, que sob a rubrica de gramática prescritiva encontram-se paradigmas que podem dialogar ou não entre si. Vale, por último, problematizar o próprio conceito de descrição. Precisamos levar às últimas consequências o fato de que a descrição, quando realizada com base em diferentes quadros teóricos, revela diferenças que não podem ser apagadas, se não quisermos simplificar o processo de compreensão do fenômeno linguístico. A TOPE como uma teoria de natureza construtivista volta-se para a compreensão do modo como os valores são construídos, neste caso em particular, por meio da operação linguístico-cognitiva referida como operação de localização. 
É preciso observar que o resultado a que chegamos por meio da análise não deve ser considerado como trazendo contribuições para que a descrição linguística se amplie. Fosse outro o quadro teórico tomado para a análise, o resultado não seria o mesmo. Como já foi dito, não consideramos os quadros teóricos complementares, salvo se pertencerem ao mesmo paradigma.

\section{Referências}

BECHARA, E. Moderna gramática portuguesa. São Paulo: Companhia Editora Nacional, $\mathrm{s} / \mathrm{d}$.

BECHARA, E. Moderna gramática portuguesa. 37. ed. rev. ampl. e atual. conforme o novo Acordo Ortográfico. Rio de Janeiro: Nova Fronteira, 2009.

CULIOLI, A. Por une linguistique de l'énonciation: opérations e représentations. Tome 1. Paris: Ophrys, 1990.

FRANCHI, C. Mas o que é mesmo "Gramática"? In: POSSENTI, S. (org.). Mas o que é mesmo gramática? 2. ed. São Paulo: Parábola, 2006. p. 11-33.

NEVES, M. H. de M. Guia de uso do Português: confrontando regras e usos. São Paulo: Editora UNESP, 2003.

REZENDE, L. M. Causalidade, propriedade diferencial e construção dos domínios nocionais. Alfa (ILCSE/UNESP), São Paulo, v. 47-2, p. 21-39, 2003.

ROCHA LIMA, C. H. Gramática Normativa da Língua Portuguesa. 32. ed. Rio de Janeiro: José Olympio, 1994.

SÃO PAULO (Estado) Secretaria da Educação, Coordenadoria de Estudos e Normas Pedagógicas. Proposta curricular para o ensino de língua portuguesa: $1^{\circ}$ grau. 3. ed. São Paulo: SE/CENP, 1988.

VOGÜÉ, S. de; FRANCKEL, J.-J. PAILLARD, D. Linguagem e enunciação:representação, referenciação e regulação. Organização de textos e de tradução: Márcia Romero, Milene Biasotto-Holmo; posfácio Valdir do Nascimento Flores. São Paulo: Contexto, 2011. 
ZAVAGLIA, A. Pequena introdução à teoria das operações enunciativas. São Paulo: Humanitas, 2010.

COMO CITAR ESTE ARTIGO: SOSSOLOTE, Cássia Regina Coutinho; ONOFRE, Marília Blundi. Mecanismos enunciativos na produção textual: reflexões sobre a noção onde. Revista do GEL, v. 17, n. 2, p. 334-348, 2020. Disponível em: https://revistadogel.gel.org.br/

DOI: http://dx.doi.org/10.21165/gel.v17i2.2825

Submetido em: 01/04/2020 | Aceito em: 19/07/2020. 